formulated and well documented, and we are throughout inspired with full confidence that the writer has not gone beyond what well-founded evidence warranted him to say. This is the line of demarcation between worthless amateur gossip about "savages" which has been the bane of anthropology, and genuine scientific information, such as is given in the present volume.

\section{B. M.}

Cours de Physique a l'usage des élèves de l'enseignement supérieur et des ingénieurs. Par Prof. Jean Becquerel. Tome premier: Thermodynamique. Pp. ix $+43^{\circ}$. (Paris: J. Hermann, I924.) 25 francs.

ThIs massive volume forms the first of a series of seven in which Prof. Becquerel proposes to deal with the various branches of physics. One cannot but feel awe as well as admiration at the boldness of such an undertaking, but if the remaining volumes reach the standard here set, the author must indeed receive our congratulations on a truly monumental work. Having faithfully accomplished the task of cutting the $43^{\circ}$ pages of the present instalment, the reviewer would earnestly request the publishers to amend their methods by subjecting the remaining volumes to the guillotine.

The author believes that in the idea of energy and in the principles of mechanics may be found a guiding line which should never be abandoned. In the introduction he is careful to insist on the experimental basis of these principles, which are presented under an aspect compatible with recent progress in physics. Before beginning the exposition of thermodynamics, which has evidently been greatly influenced by the work of Planck and of Poincaré, the author discusses the discontinuous structure of matter and the kinetic theory of gases, acknowledging his indebtedness to the books of Eugène Bloch and of Jean Perrin. By the aid of the kinetic theory and the idea of the disordered movement of the molecules, the principle of Carnot is rendered less abstract. The statistical theory of thermodynamics, in which the author follows closely an exposition given by Langevin, gives precision to this idea.

As a descriptive treatise the book is an excellent one; the difficulties and mistakes of the student are carefully considered, but a British engineer would expect to find more attention paid to the numerical application of the theoretical results. H. S. A.

The Atmosphere and its Story : a Popular Presentation of the Science of Meteorology, free from Technicalities and Formule. By Ernest Frith. Pp. $204+9$ plates. (London: The Epworth Press, 1924.) 6s, net.

IN his preface the author explains that this book is the outcome of daily explanations of the weather given to classes in meteorology at Clark University. The notes of these classes, collected and amplified, are here presented in book form.

The book is divided into four parts, one for each season of the year, the first section of Part I. giving a few brief notes on methods of observation of wind, temperature, humidity, rainfall, and snowfall. There follows a simple account of various physical processes in the atmosphere, supplying answers to many of the questions concerning the weather which strike the intelligent man in the street. The author writes in the first place for Americans, and the details he discusses are the details of American meteorology. In spite of this, however, his book can be recommended to the general English reader as a useful introduction to weather phenomena. It is very well illustrated, the cloud pictures being in all cases selected from the U.S. Weather Bureau's new cloud chart.

The author discusses in an interesting and instructive manner the rôle of moisture in the air, and the formation of fog, cloud, and rain. The topics in each seasonal part are selected so as to appeal to the general reader, and discussed in such a clear manner as to instruct that reader in the physical processes which underlie weather. The author has succeeded in writing a book which should appeal to a very wide public.

Electric Cables, their Design, Manufacture and Use: a Series of Lectures delivered in the Moore School of Electrical Engineering of the University of Pennsylvania. By William A. Del Mar. Pp. vii +208 . (New York: McGraw-Hill Book Co., Inc. ; London : McGraw-Hill Publishing Co., Ltd., r924.) r2s. $6 d$. net.

THIs treatise gives a good account, both historical and scientific, of cable manufacture. Wire was originally made by beating metal into plates, which were then cut into strips and rounded by hammering. It is stated that the art of drawing metal through dies was probably invented in the fourteenth century, although it did not come into practical use in Great Britain before the second half of the seventeenth century. The Birmingham Wire Gauge was the first attempt to standardise sizes. The first scientific attempt was made by Brown and Sharpe in America in 1855 . The diameters of the wires they fixed form a regular geometrical progression from the English size of No. $3^{6}$ (5 mils) to $4 / 0$ (460 mils). As there are 40 sizes, the common ratio is the 39 th root of 92 , which is $I \cdot I 23$ nearly. This gauge is now officially called the "American Wire Gauge."

It is interesting to see that the formulæ first given in Fourier's "Théorie analytique de la chaleur" are in everyday use in cable work. Approximate values of the thermal conductivities of all the ordinary insulating materials used for cables are given, and the question of the grading of cables so as to enable them to resist puncturing by high voltages is discussed at length. There is, however, a great deal of work still to be done, both by the mathematician and the physicist, before definite conclusions as to the value of the method can be reached.

Crystals and the Fine-Structure of Matter. By Prof.

Friedrich Rinne. Translated by Walter S. Stiles. Pp. ix + r95 + I5 plates. (London: Methuen and Co., Ltd., I924.) ros. 6 d. net.

THIs translation has been made from the second edition of Prof. Rinne's book on fine-structure of matter, which he has named Leptology ( $\lambda \epsilon \pi \tau$ rós). According to the preface the book was written largely for the general reader, but discussion of a large number of aspects of the subject (there are fifteen chapters) has necessitated much condensation, and it is doubtful if much of the matter will be intelligible to the layman. This is noticeable in Chap. iii., "Crystallography and

$$
\text { NO, } 29 \text { IO, VOL. I I 6] }
$$

